\title{
Risk Factors of Biliary Peritonitis following T-Tube Removal- The Unsolved Problem
}

\author{
Partha Pratim Barua ${ }^{1}$, Devid Hazarika², Khorshid Alom Hussain ${ }^{3}$ \\ ${ }^{1}$ Associate Professor, Department of Surgery, Fakhruddin Ali Ahmed Medical College, Barpeta, Assam, India. \\ ${ }^{2}$ Assistant Professor, Department of Surgery, Assam Medical College, Dibrugarh, Assam, India. \\ ${ }^{3}$ Registrar, Department of Surgery, Fakhruddin Ali Ahmed Medical College, Barpeta, Assam, India.
}

\section{ABSTRACT}

\section{BACKGROUND}

Gall stone disease remains one of the most common problems leading to surgical intervention. About $15 \%$ of all gall stone disease patients have stones in the common bile duct (choledocholithiasis). Open choledocholithotomy is still widely performed, particularly in centres without ERCP facilities. Though primary repair of the common bile duct is possible, most surgeons prefer to drain the common bile duct with T-tube. This avoids pressure build up in the CBD in case of oedema around the ampulla of Vater in the immediate post-operative period. Normally, the T-tube is left for 14-20 days in order to allow a fibrous tract to form around it. In absences of any distal obstruction, the T-tube is removed by gentle traction in the horizontal limb. In majority of the cases no complications occur after tube removal. However, in some patients, biliary peritonitis occurs with varying severity. The aim of this study is to find out if there are yet unrecognized factors that increases the risk of biliary peritonitis post T-tube removal.

\section{METHODS}

A case control study was done in our rural based tertiary hospital with patients undergoing cholecystectomy and choledocholithotomy in between July 2017 and June 2018 in all surgical wards. 18 cases who had complications following T-tube removal were taken as cases (Group B). All these cases were females in the age group 20 to 45 years. None of these patients had other risk factors like diabetes, jaundice or any cause for immunosuppression. 36 cases comparable with regard to age, sex and pre-operative health status and who did not have any complications after tube removal were taken as control (group A). Data from these two groups was recorded under two headings -1) patient related. 2) technique related. Data was entered in excel sheet and analysis was done to see if there are any significant differences between the two groups either in patient related or technique related factors.

\section{RESULTS}

Patient related factors like duration of disease, $\mathrm{Hb} \%$, liver function test etc, were compared between group A and group B but no statistically significant difference was found. Of the technique related factors, no significant difference was noted between the two groups as far as removal of T-tube time was concerned. However statistically significant difference was noted when suture material used to repair the CBD was considered, with $55.55 \%$ of cases in group B showing the use of Vicryl (Polyglactin) as compared to $22.22 \%$ in group $\mathrm{A}$.

\section{CONCLUSIONS}

It was observed that a significantly higher number of patients had complication following T-tube removal when the CBD was repaired with Vicryl suture as compared to patients where Catgut suture was used.

\section{KEY WORDS}

Cholecystitis, Choledocholithiasis, T-Tube, Biliary Peritonitis
Corresponding Author:

Devid Hazarika,

Gunjan's Aparna Enclave,

Hatigarh Chariali, Geetanagar,

Guwahati-781021, Assam, India.

E-mail:drdevidgmc@gmail.com

DOI: $10.14260 / j e m d s / 2019 / 546$

Financial or Other Competing Interests: None.

How to Cite This Article:

Barua PP, Hazarika D, Hussain KA. Risk factors of biliary peritonitis following $t$ tube removal - the unsolved problem. J. Evolution Med. Dent. Sci. 2019;8(31): 25092513, DOI: $10.14260 /$ jemds/2019/546

Submission 23-05-2019,

Peer Review 21-07-2019,

Acceptance 27-07-2019,

Published 05-08-2019. 


\section{BACKGROUND}

Gallstone disease remains one of the most common medical problems leading to surgical intervention. In the USA, approximately 500,000 cholecystectomies are done every year.(1) It affects $10 \%$ of the adult population in USA. Biliary tract disease are more common in female with the male: female incidence during reproductive age being 4:1. Among the Asian countries Taiwan reportedly as the highest incidence of biliary tract calculi, with the average figure for the whole

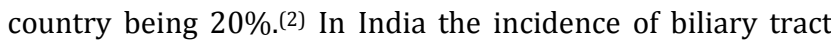
stone disease was reported to be $26.7 \%$ among parous women in Kashmir.(3) Rakesh K Tandon, in a study conducted among the population of Delhi, gave the incidence of gall stone at $4.3 \%$, but admitted that there was a tremendous difference among different ethnic groups. He reported a very high incidence in north Indians, particularly among the Punjabis, and a low incidence in south Indians.(4) Biliary tract stone diseases are more common in females than males in India. A study from a south Indian tertiary hospital found the sex incidence to be twice in females than in males. (5)

In our tertiary hospital located in a rural area and which caters to almost 5 districts of lower Assam the incidence of biliary tract disease is found to be very high. Almost $28.6 \%$ of all OPD attendance in surgery is due to biliary tract stone disease. Cholecystectomy with choledocholithotomy where indicated is the commonest major surgical procedure in this hospital. About $15 \%$ of all gall stone diseases are complicated by slippage of stones to the common bile duct.(6) Primary duct stones may occur but are far less common. Bile duct stones may pass to the duodenum asymptomatically, cause biliary colic, obstructive jaundice, or pancreatitis when impacted at the ampulla of Vater.(7)

Modern treatment of cholelithiasis with choledocholithiasis is laparoscopic cholecystectomy with endoscopic retrograde cholangiopancreatography (ERCP), where CBD calculi are removed by instrumentation through the ampulla of Vater. However, in failure of ERCP, or in institutions where such facilities are not available, choledocholithiasis is still treated with open surgery. Open choledocholithotomy is commonly followed by T-tube drainage of the CBD instead of primary repair. This is done as it is feared that instrumentation by choledocholithotomy forceps can result in post-operative oedema around the ampulla, leading to pressure build up in the CBD. The long arm of the T-tube connects the opening in the CBD to the exterior. Because of the irritative nature of the tube material, a fibrous tract forms around the intra-abdominal part of the T-tube in 10- 12 days. After a routine post-operative T-tube cholangiogram is found to be normal, the T-tube is removed by gentle traction on the long arm. Small amount of bile that may leak from the opening in the CBD comes to the exterior through the fibrous tract. In absence of any distal obstruction in the CBD, the tract closes on its own.

However, it has been seen that T-tube removal is occasionally complicated by bile leak to the peritoneal cavity causing biliary peritonitis, thus causing the very problem it was meant to prevent $(8)$. The incidence of biliary peritonitis after T-tube removal have been reported to be from $2.5 \%$ $19.6 \% .^{9}$ ) In our institution also, we have encountered such complications and the incidence has been found to be around $16 \%$. This is despite the fact that all known risk factors, like use of improper material, early removal of tube or improper positioning of T-tube has been avoided. Also, this incidence is found among seemingly healthy patients without immunosuppression.

The aim of this study is to find out through a retrospective data analysis between two similar groups- one with complication after tube removal, and the other without any such complications - to find out if there are any additional factors that could increase the risk of complication after T-tube removal.

\section{METHODS}

A proposal for the study was sent in the prescribed format to the Institutional Ethical Committee and permission obtained. As the study is a retrospective observational study, the question of patient consent did not arise, particularly as all the data are unidentified, with no mention of patient's name, hospital No., registration No. etc. However, permission was taken from Superintendent of the hospital for using hospital data. A case control study was done with the data of patients operated in all surgical units in our rural based tertiary hospital for cholelithiasis and choledocholithiasis in between July 2017 to the end of June 2018. 18 cases who had developed some complications after T-tube removal and who did not have any risk factors like diabetes, immunocompromised state, cardiac or pulmonary diseases where selected to be included in this study as cases (group B). None of these patients had jaundice at the time of operation. All these patients were females of the age group between 20 to 45 years. 36 similar patients who were operated for the same condition and who showed no complications at the time of T-tube removal were selected as control group (group A). All the cases included in group A were also of the same age group and all of them were females. None of these cases had pre-existing risk factors and were not jaundiced at the time of operation.

All the cases (group A + group B) had undergone routine pre-operative investigations including blood investigations, chest X-ray, and ECG. Diagnosis of cholelithiasis and choledocholithiasis was done by ultrasonography. Ultrasound was repeated on the day prior to operation in all cases. All cases were put on IV antibiotics (Piperacillin + Tazobactam) from the day prior to surgery. IV metronidazole was given all cases for 5 days post-operative. Oral antibiotics (Ciprofloxacin) was given in all cases from $10^{\text {th }}$ post- operative and was continued up to the time of T-tube removal.

Latex T-tubes were used in all cases. Vertical guttering of the small limb of the tube with a $V$ wedge cut from the junction of the T-limb with the horizontal was done in all cases. T-tube cholangiogram was done in all cases on the $10^{\text {th }}$ post-operative day. Post-operative cholangiogram was normal in all cases. Ttubes were subsequently clamped for increasing periods before being removed by gentle traction. None of the cases had tube removed before $15^{\text {th }}$ post-operative day.

In order to identify the cause of why certain patients still develop complication after T-tube removal, the data of the two groups were compared under two headings-

1. Patient related factors- a) duration of disease. b) $\mathrm{Hb} \%$. c) Serum albumin level. d) SGOT. e) SGPT. 
2. Technique related factors- a) suture material used to repair CBD. b) Time of T-tube removal post-operative.

Data was entered in Excel Sheet and analysis was done using MS Excel. Z-value and chi-square value where appropriate were calculated for group A and B.

\section{RESULTS}

\begin{tabular}{|c|c|c|c|c|}
\hline Factors & Group A & Group B & p & Result \\
\hline & $\begin{array}{c}\text { Median (Inter } \\
\text { quartile range) }\end{array}$ & $\begin{array}{c}\text { Median (Inter } \\
\text { quartile range })\end{array}$ & $\begin{array}{c}\text { Significance } \\
\text { level at } 0.05\end{array}$ & \\
\hline SGOT & $42(28)$ & $42(19)$ & 0.727 & $\begin{array}{c}\text { Retain the null } \\
\text { hypothesis }\end{array}$ \\
\hline SGPT & $57.5(50)$ & $66(34.5)$ & 0.920 & $\begin{array}{c}\text { Retain the null } \\
\text { hypothesis }\end{array}$ \\
\hline \multicolumn{5}{|l}{ Table 1. Comparison of SGOT and SGPT Between Group A and Group B } \\
\hline
\end{tabular}

\begin{tabular}{|c|c|c|c|c|c|c|c|c|c|}
\hline$\frac{0}{2}$ & 苞 & 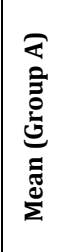 & 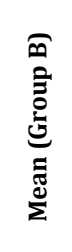 & 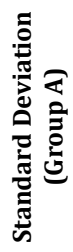 & 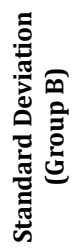 & 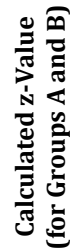 & 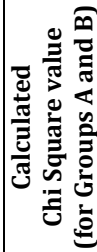 & 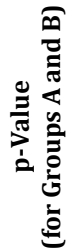 & $\stackrel{\stackrel{n}{ت}}{\vec{y}}$ \\
\hline \begin{tabular}{|l|l}
1 \\
\end{tabular} & Albumin & 4 & 4.2 & \begin{tabular}{|l|}
0.199 \\
\end{tabular} & \begin{tabular}{|l|}
0.202 \\
\end{tabular} & -1.43 & - & 0.076 & \multirow{4}{*}{$\begin{array}{c}\text { Retain the } \\
\text { null } \\
\text { hypothesis }\end{array}$} \\
\hline 2 & $\begin{array}{l}\text { Duration } \\
\text { of disease }\end{array}$ & 6.26 & 5.25 & 39.99 & 21.4 & 0.66 & - & 0.255 & \\
\hline 3 & $\mathrm{Hb} \%$ & 11.6 & 11.94 & \begin{tabular}{|l|}
1.58 \\
\end{tabular} & \begin{tabular}{|l|}
2.05 \\
\end{tabular} & -0.87 & - & 0.19 & \\
\hline 4 & $\begin{array}{c}\text { T-Tube } \\
\text { Removal } \\
\text { Time } \\
\text { (in days) }\end{array}$ & 20.28 & 21.11 & 3.76 & 5.1 & -1.34 & - & 0.09 & \\
\hline
\end{tabular}

Table 2. Distribution of Other Baseline information

Comparison of patient related factors between group A and B showed no statistically significant difference. Similarly, post-operative T-tube removal time (in days) between the two groups showed no significant difference (P value 0.09).

\begin{tabular}{|c|c|c|c|}
\hline Group & Vicryl & Catgut & Total \\
\hline Group -A & $8(22.22 \%)$ & $28(77.77 \%)$ & 36 \\
\hline Group -B & $10(55.55 \%)$ & $8(44.44)$ & 18 \\
\hline Total & $\mathbf{1 8}(\mathbf{3 3 . 3 3 \%})$ & $\mathbf{3 6}(\mathbf{6 6 . 6 6} \%)$ & $\mathbf{5 4}$ \\
\hline \multicolumn{4}{|c|}{ Table 3. Showing Suture Material Use in Group A and B } \\
\hline
\end{tabular}

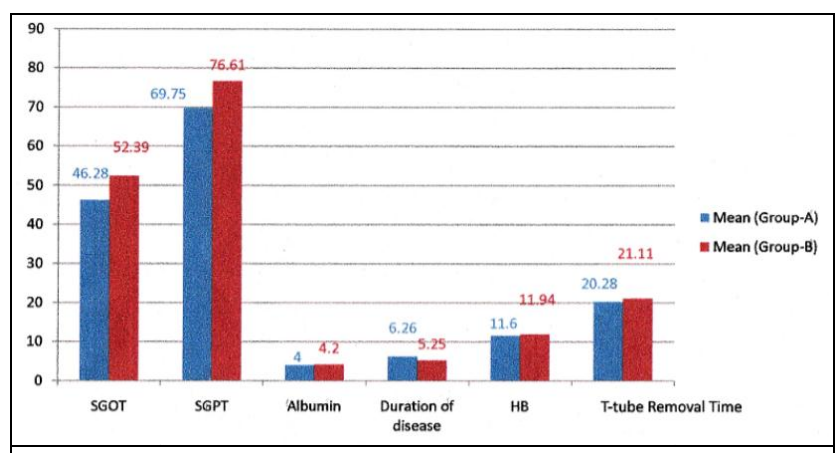

Figure 1. Bar-Diagram Showing Mean of Factors of Group A and B

28 of the 36 patients in group A (without complication) had the CBD repaired with chromic catgut 3-0, (77.77\%) whereas 8 patients had the repair done with Vicryl 3-0 $(22.22 \%)$. In group B (with complication) 10 of the 18 patients had the repair done with Vicryl 3-0, (55.55\%) and 8 patients had the repair done with chromic catgut 3-0, (44.44\%). Using the above table Chi-Square value (for group A and B) was calculated and found to be 5.531. P-value was found to be 0.019 . This result is significant at $\mathrm{P}<0.05$. So null hypothesis is rejected.

\section{DISCUSSION}

Open cholecystectomy with choledocholithotomy is still widely practiced in our hospital in the absence of ERCP facility. In all cases undergoing choledochotomy, the common bile duct is drained post-operatively by T-tube drain. T-tube placement allows decompression of the biliary tract in case of postoperative oedema around the ampulla. It also allows access to the common bile duct for post-operative T-tube cholangiogram. Missed stones can be extracted through a mature tract formed by the T-tube by choledochoscope.(10,11) Many authors have however promoted primary closure of the common bile duct and claimed that no serious post-operative morbidity occurs after such a procedure. Others have used alternative methods like retrograde trans -hepatic biliary drainage (RTBD), trans-cystic tube drainage, endonasobiliary (ENBD) tube etc., keeping in line with the need for biliary drainage following choledochotomy. Trans duodenal exploration removes the need for choledochotomy, but has high mortality and morbidity, specially from post-operative pancreatitis.(12) Choledocho-duodenotomy is useful in multiple or recurrent calculi, but can be done only if the duct is grossly dilated.(13) Once a T-tube is placed, it is kept for a minimum of 12 to 14 days to allow a mature tract to form around the horizontal tube. If post-operative cholangiogram is found to be normal, the T-tube can be safely removed by gentle traction. As any bile, which may leak through the gap in the common bile duct, flows to the exterior through the tract, there normally is no contamination of the peritoneal cavity. Peritonitis following T-tube removal was thought to be a rare occurrence. However, review of literature show that the incidence is not negligible. In our centre $16 \%$ of cases undergoing choledochotomy with T-tube placement showed complications of varying severity after tube removal.

Maghsoudi $\mathrm{H}$ et al reported that the incidence of peritonitis after T-tube removal range from $2.5 \%$ to $19.6 \%$. Gillatt DA, May RE et al reported the incidence to be $19.4 \% .(14)$ However, in their series, T-tube removal was done at the end of first week post-operative. In immunocompromised patients, such as those on corticosteroids, the incidence of peritonitis after tube removal is reported to be as high as $50 \%$.(15) In another study comprising 139 patients the reported incidence of complications after tube removal was $4.3 \%$.(16) Corbett CRR et al in a study done in south east Thames region however reported the incidence of peritonitis after tube removal to be as low as 1 out of every 119 exploration.(17) Severe pain abdomen, starting within 2 hours of tube removal was present in all 18 cases of group B in this study. The pain was mostly felt in the right shoulder region and in the right hypochondrium. Pain was severe enough to require repeated doses of either inj. Diclofenac $75 \mathrm{mg}$ or inj. Tramadol Hydrochloride. Fever was recorded $\left(99^{\circ} \mathrm{F}\right.$ to $\left.101^{\circ} \mathrm{F}\right)$ in 10 cases $(55.55 \%)$ within 12 hours of tube removal. 5 cases $(27.7 \%)$ had repeated episodes of vomiting and required Ryles tube intubation and aspiration. In 17 of the total of 18 patients in group B, the symptoms resolved by conservative measures, with signs of recovery being apparent within 48 hours. In 1 patient (5.57\%) reexploration with drainage of collected bile was required.

Case records in two large public hospitals in New South Wales (Australia) were analysed retrospectively and complications following planned T-tube removal was 
recorded in 42 of 274 cases $(15.3 \%)$ of these localised pain was found to be the commonest symptom, followed by symptoms of frank biliary peritonitis, prolonged biliary fistula and late bile duct stricture (18). In 6 cases of complications recorded in another study, pain was found in all 6 , fever in 5 cases, tenderness in 4 cases, and chill in 3 cases. The authors reported that in all cases symptoms resolved between 4 hours to 8 days without surgical intervention. Sharma $M$ et al in an article published in 2016 recorded complications in 10 of 40 patients (25\%). 4 patients had pain abdomen, 2 patients had vomiting, 1 patient had symptoms of cholangitis, 2 patients had frank biliary peritonitis requiring re-exploration and 2 patients had wound infection(19).

Several previous studies have attributed different causes for complications occurring after T-tube removal. Gillatt DA (14) reported a $19.4 \%$ incidence of complications when T-tube were removed after 7 days post-operative. On the other hand, Meghsoudi $\mathrm{H}$ et al in their study found that the incidence of such complications were only $2.5 \%$ when T-tube were kept for 21 days. They also reported that no additional benefits were found by keeping the T-tube for as long as 6 to 12 weeks studies have also concluded that the fibrous tract between the bile duct and skin may get disrupted leading to extravasation of bile to the surrounding tissue.(16) Ehson Sultan et al.(15) Suggested that prior to removal of the tube a tractogram should be performed by injecting 5 to $10 \mathrm{~cm}^{3}$ of Urografin by a $24 \mathrm{G}$ cather pushed between the skin and the tube. Infected bile is thought to be another cause of complication following T-tube removal. In the study reported by Gillatt DA.(20) it was stated that 21 of the 36 patients in their series had organism in the bile culture, mostly of E.coli. Sharma M et al(19) also concluded that most of the cases of choledocholithiasis harbour organism in the bile that could lead to complications. They recommended that bile culture should always be done in all cases of choledocholithiasis. T-tube material is also a thought to be an important factor in determining the outcome. Since tissue reaction to the material is important for a good fibrous tract to form, the material of the tube should be able to evoke a good tissue reaction. Latex is thought to be the best material for the T-tube. The material of the T-tube and the technique of duct suture are said to be more important factor than the duration of duct intubation. Daldoul $\mathrm{S}$ et al(21) concluded in their study that this problem has multiple causes. Some are patient related (Corticosteroid therapy, chemotherapy) whereas others are technical factors (Inappropriate suturing of duct wall, improper drain material).

In our institution we follow a strict protocol, where all known risk factors are avoided. Only Latex T-tubes are used in all cases. T- tubes were removed only after a post-operative $T$ tube cholangiogram showed no distal obstruction. In all cases T-tubes were clamped for increasing periods before removal. In no case were $\mathrm{T}$-tubes removed before $14^{\text {th }}$ post-operative day. All cases were under injectable and later oral broadspectrum antibiotics from the pre-operative day up to the time of T-tube removal. Despite these precautions we have a significant incidence $(16 \%)$ of cases showing complications after T-tube removal. In order to study if there are any additional factors which play a part, we retrospectively analysed the data of 18 patients who showed complications after tube removal (Group B) with 36 similar patients as far as age, sex and per-operative health status is concerned, and who showed no complications after T-tube removal. Comparison was done in two headings- a) patient related factors. B) Technique related factors. While no significant difference was found between the two groups as far as patient related factors are concerned, it has been seen that in group B (Complicated group) Vicryl was used as a suture material in a majority of cases 56\%, whereas in group A (Uncomplicated group) it was used in only $22 \%$ with chromic catgut being used in the remaining cases in both groups. This difference was found to be statically significant. While the reason behind this finding is not clear it is known that Vicryl (Polyglactin) retains tensile strength in vivo for a longer period (half lost in 15 days) as compared to chromic catgut (2/3 lost in 10 to 15 days). A greater force may be required to pull the T-tube for removal in presence of intact sutures around the tube, which may cause injury to the tract. Also, catgut evokes a greater inflammatory tissue response as compared to polyglactin, which evokes muted or very slight inflammatory reaction. A study involving larger number of subjects with a good study design will be required to bring greater clarity to the subject.

\section{CONCLUSIONS}

Vicryl was used in a significantly greater number of cases that had complications following T-tube removal as compared to patients who had no complications following tube removal, and where catgut was the more frequently used suture material.

\section{REFERENCES}

[1] Schirmer BD, Winters KL, Edlich RF. Cholelithiasis and cholecystitis. Journal of Long Term Effects of Medical Implant 2005;15(3):329-38.

[2] Su CH, Lui WY, Peng FK. Relative prevalence of gall stone disease in Taiwan. A nationwide cooperative study. Digestive Diseases and Science 1992;37(5):764-8.

[3] Khuroo MS, Mahajan R, Zargar SA, et al. Prevalence of biliary tract disease in India: a sonographic study in adult population in Kashmir. Liver, Biliary and Pancreas. Gut 1989;30(2):201-5.

[4] Tendon RK. Prevalence and type of biliary stones in India. World Journal of Gastroenterology 2000;6(Suppl 3):4-5.

[5] Parambil SM, Matad S, Soman KC. Epidemiological, demographic and risk factor profile in patients harbouring various types of gall bladder calculi: a cross sectional study from a south India tertiary care hospital. International Surgery Journal 2017;4(2):525-8.

[6] Arain MA, Freemen ML. Choledocholithiasis: clinical manifestation, diagnosis and management. https/www.uptodate.com.

[7] Siddiqui AA. Choledocholithiasis and Cholingitis. https/www. merekmanuals.com.

[8] Gurusamy KS, Koti R, Davidson BR. T-tube drainage versus primary closure after open common bile duct exploration. Cochrane Database Syst Rev 2013;(6):CD005640.

[9] Maghsoudi H, Garadaghi A, Jafary GA. Biliary peritonitis requiring re-exploration after removal of T-tube from common bile duct. Am J Surg 2005;190(3):430-3. 
[10] Thoraton JK. Observation on additional cases illustrating hepatic surgery. Lancet 1891;137:763-4.

[11] Randale FF, Cass MH, Robson B, et al. Bile drainage after choledochotomy in man, with some observation on biliary fistula. J Surgery 1955;37(6):903-10.

[12] Cave-Bigley DJ, Aukland P, Kane JF, et al. Transduodenal exploration of the common bile duct in a district general hospital. Ann R Coll Surg Engl 1984;66(3):187-9.

[13] Johnson AG, Rains AJ. Choledochoduodenostomy. A reappraisal of its indication based on a study of 64 patients. Br J Surgery 1972;59(4):277-80.

[14] Gillatt DA, May RE, Kennedy R, et al. Complications of Ttube drainage of the common bile duct. Ann R Coll Surg Engl 1985;67(6):370-1.

[15] Soltani E, Bahar MA, Dehghanian P, et al. Prevention of biliary leakage after removal of T-tube in immunocompromised patients. Indian J Surg 2015;77(Suppl 2):645-9.

[16] Dellinger EP, Steer M, Weinstein M, et al. Adverse reactions following T-tube removal. World Journal of Surgery 1982;6(5):610-15.
[17] Corbett CRR, Fyfe NCM, Nicholls RJ, et al. Bile peritonitis after removal of T-tube from common bile duct. British Journal of Surgery 1986;73(8):641-3.

[18] Will VL, Gibson K, Karihaloot C, et al. Complication of biliary T-tube after choledochotomy. ANZ J Surg 2002;72(3):177-80.

[19] Sharma M, Choudhury S, Sharma R, et al. A prospective study of complications of T-tube drainage of common bile duct in the management of choledocholithiasis in a tertiary care hospital of North India. IOSR Journal of Dental and Medical Sciences 2016;15(10):09-13.

[20] Gillatt DA, Kelly MJ. Biliary leakage requiring re-operation following T-tube removal. Surgical Research Communication 1987;1(3):195-8.

[21] Daldoul S, Moussi A, Zaouche A. T-tube drainage of the common bile duct - choleperitonium: etiology and management. Journal of Visceral Surgery 2012;149(3):e172-8. 